\title{
La nueva pandemia y la verdadera crisis del sistema de salud en el Perú
}

\author{
The new pandemic and the true crisis of the health system in Peru
}

\section{Señor editor:}

Con la pandemia, está expuesta la crisis del sistema de salud: falta de infraestructura, equipamiento, escasez de profesionales, etc. Esto revela la falta de liderazgo y organicidad en la actividad sanitaria; sin organicidad y sin liderazgo no cabe gobernanza razonable y el caos se hace manifiesto.

Una crisis así exige pensar en una solución integral. Albert Einstein afirmaba: "locura es hacer la misma cosa una y otra vez esperando obtener diferentes resultados" (1), entonces toca aplicar cambios considerables al sistema de salud, pero ¿cuáles?

Hoy los esfuerzos sanitarios son fragmentados y desarticulados. No es posible hablar de "gestión de la modernidad en salud" en organizaciones burocráticas con alto grado de especialización y segmentación del trabajo (como en redes hospitalarias), numerosas reglas y centralización para decidir ${ }^{(2)}$.

En los hospitales, la sobre especialización, fragmentación por servicios, premura por la hipertecnología, pobre comunicación, desconocimiento de los agentes que participan en el dinamismo de las organizaciones, son también parte del desgobierno en salud y desenfocan los objetivos globales de la actividad médica.
El liderazgo no puede recaer en una sola persona, necesitamos multitud de liderazgos y de agentes de cambio. Se requiere de un liderazgo orgánico ${ }^{(3)}$, frente al mecanismo fragmentario e individualista. Se requieren también de organizaciones orgánicas: actividades interrelacionadas, buena comunicación y descentralización en la toma de decisiones ${ }^{(4)}$. En definitiva, el liderazgo debe empoderar a todos y no sólo a los funcionarios públicos.

Pensando orgánicamente, ¿quiénes son los líderes? El liderazgo radica en la ética, riqueza interior, que trabajando sincronizada y orgánicamente es capaz de hacer crecer hacia el interior a sus organizaciones $\mathrm{y}$ a sus miembros, las hacen madurar y adquirir organicidad propia: inteligencia compartida en equipo. Es necesaria una re-invención y un re-pensamiento para un sistema ajustado a nuestros recursos y a nuestra situación histórica.

Necesitamos un liderazgo humanista, la persona debe estar al centro de la organización y organizar todo a favor de ella, priorizando el bien común e integrándolo (agentes, áreas, servicios). Practicar el "humanismo empresarial": espíritu superior y real ${ }^{(5)}$, esclarecedor y más fecundo que lo ya incrustado en occidente: llenar los bolsillos y reducir todo a lo económico, y así el bien común ya no es una obligación moral ${ }^{(6)}$.

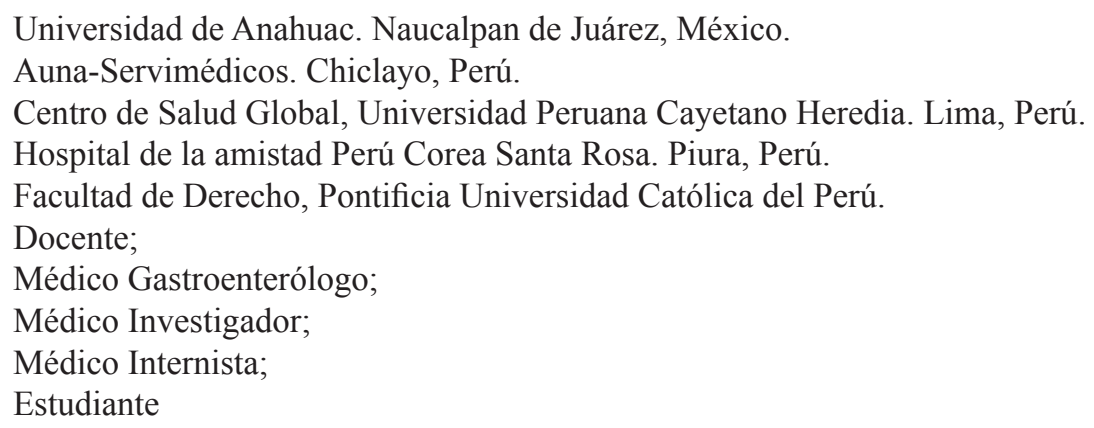


Desde este enfoque: curriculismo, burocratización, práctica mercantilista, corrupción directiva o salarios indignantes, anulan la gobernabilidad y con ella el servicio a la sociedad. El nuevo sistema de salud tendrá un organigrama gobernable, con personas íntegras, con gestión de procesos que permita obtener resultados eficaces y eficientes, priorizando la unidad y la confianza ${ }^{(7)}$.

Los funcionarios, deben brindar una confianza que nos dé "la victoria sobre el tiempo: no nos debe asustar su pasado, para creer en su presente y así ser capaces de apostar un futuro" con estos líderes ${ }^{(8)}$.

De fondo, la falta de liderazgo sanitario está íntimamente ligada con la pérdida de la vocación médica: proceso que se genera en el interior de cada persona y tiene un factor social ${ }^{(9)}$ ¿Qué pasa en los centros de formación médica? Están ideologizadas por el mito del progreso y el principio del resultado ocasionando la deshumanización de la medicina y sobre todo del médico ${ }^{(10)}$.

Los sistemas de salud sometidos a la presión económica de las leyes de mercado, la relación médicopaciente despersonalizada, incremento de tareas administrativas, convierten al médico en el hospital en un funcionario ${ }^{(11)}$, deteriorando así la naturaleza de la vocación médica: el servir.

La situación es de alta complejidad, pero cabe esperanza en solución si cambiamos el enfoque de la gobernanza y empezamos a dirigir centrados en las personas y no sólo en los objetivos.

\footnotetext{
Alberto Vargas ${ }^{1, a}$, Fernando Cubas Benavides ${ }^{2, b}$,

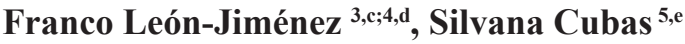

\section{REFERENCIAS BIBLIOGRÁFICAS}

1. Homo Investor. La importancia de hacer seguimiento de las finanzas personales. Homo Investor; 2016. (Citado el 12 de febrero del 2021) Disponible en: https://www.homoinvestor.com/2016/11/17/laimportancia-de-hacer-seguimiento-de-lainformacion-financiera

2. Claver C, Pertusa E, Molina J. Caracterización de las estructuras mecánica y orgánica a partir de las principales dimensiones estructurales. Investigaciones Europeas. 2006; 12:187-204.

3. Barrios C. El liderazgo Orgánico. Buenos Aires, Argentina: Schoenstattianos en red; 2009. (Citado el 25 de mayo de 2020). Disponible en: https://www. schoenstatt.org/images/uploads/material $\% 20$ pdfs\%20general/cultura-de-la-alianza/carlos-barriosliderazgo-organico-17-11-2009.pdf

4. Burns T, Stalker G. The Management of Innovations. Tercera Edición. Oxford: Editorial Oxford University Press; 1994.

5. Alvira R. ¿Qué es el humanismo empresarial? Cuadernos de Empresa y Humanismo 1989; 17:2-15.

6. De-Sendagorta E. El humanismo en el liderazgo empresarial. Revista de Empresa y Humanismo. 2008; 11(2):11-32.

7. Alcázar M, Ferreiro P. Gobierno de personas en la empresa. Séptima Edición. Perú: Editorial Create Space Independent; 2017.

8. Alvira R. Humanismo empresarial para la mejora de la sociedad. Rev Ciencias empresariales y economía. 2002; 1:7-11. (Citado el 25 de mayo de 2020). Disponible en: http://www.um.edu.uy/docs/ revistafcee/2002/humanismoempresarialAlvira.pdf

9. Perales A, Mendoza A, Sánchez E. Vocación médica en médicos de prestigiada conducta profesional. An Fac med. 2013; 74 (4):291-300.

10. Cubas F, Vargas A, León F, Lecanda J. ¿La ciencia moderna y la medicina se encuentran en crisis? Rev Med Hered. 2016; 27:121-122.

11. Castillo Ch. ¿Qué está pasando con los valores profesionales en la formación de los médicos?: Visión del alumno. Educación Médica. 2016; 9 (Suplemento 1):9-11.

Recibido: 28/07/2020

Aceptado: $14 / 12 / 2020$ 